\title{
Understanding human resilience in the context of interconnected health and social systems: Whose understanding matters most?
}

\author{
Astier M. Almedom $^{1}$
}

Key Words: epistemological plurality; health and social systems; human resilience

\section{INTRODUCTION}

Human resilience is an intuitive response to extreme adversity and/or acute stress observed across the life course. It is now better understood than ever before because it manifests in children, adolescents, adults, senior citizens, and the elderly at the individual level. We now know also that human resilience does not exist in a vacuum; it is embedded in functional human relationships and healthy interactions of the individual with the immediate social, cultural, economic, and biophysical environment. When the social-ecological systems and subsystems present threats to human lives and livelihoods, or are threatened by human actions and modes of livelihood, human resilience takes multidimensional forms and meanings.

Previously presumed to be the absence of psychosocial pathology, this century has opened up many doors and windows of opportunities for the study of human resilience outside the confines of psychology and sociology through interdisciplinary and transdisciplinary methods and tools of enquiry. It is now well understood that the phenomenon of human resilience to extreme levels of acute stress and prolonged adversity calls for complex combinations and arrays of innate as well as acquired assets and capabilities. From the smallest social units of couples and families to the larger community organizations and social networks, elements of human resilience are identifiable. These include the capacity to anticipate and judiciously engage with adverse events and experiences by maintaining "normal" functions while undergoing transformative changes without loss of core identity and integrity.

This is well understood even if it is not articulated as such by ordinary women and men whose lived realities spell human resilience. It may be a puzzle however to many scholars and researchers looking in from the outside, trying to grasp the meaning of the word resilience, which to them it is a disembodied term. Lay people may sum up human resilience as "thriving and not merely surviving against the odds," as my study participants did in Eritrea in 2001 when the topic formally took shape as a research question. How does one assess, understand, and explain to others what thriving and not merely surviving against the odds really means? Why does it matter? Whose understanding matters most and why?

There are two main obstacles that stand in the way of understanding human resilience. The first one is epistemological supremacy that imposes limits on the modus operandi of many a scholar and researcher who is tied to discipline-specific approaches to the study of human resilience. The second is the absence of skills and resources to truly engage multiple perspectives meaningfully, with intent to enhance and promote human resilience among those who live it.

Human resilience has always been well understood by the people who live it. They articulate it in their own words using their own languages. For example, in Tigrinya, my mother tongue, human resilience (physical, emotional, and mental) is summed up by a four-letter word: : $^{\prime 3} 39^{\prime}$ ' (commonly transliterated as Tsin'At). The word is imbued with a multidimensional set of meanings that evoke mental, emotional, and spiritual insight, resolve, foresight, strength, and fortitude in an individual and in a communal social context. In this case, there is no need to preface it with "human" because that is implicit. However, in the English language, the word resilience (British) or resiliency (American) may not immediately be understood as a human (psychosocial) characteristic. It is often associated with the biosphere, for example, in ecology and environmental sciences; man-made physical infrastructure, such as buildings, bridges, and communication systems; and complex systems of resource management involving financial and social-ecological assets and liabilities. Although human interactions are part and parcel of all these systems, human resilience per se is often not the first thing that comes to mind when the systems' resilience is the focus of attention. However, the people who work in these systems, particularly those in supervisory and/or executive positions are expected to be "hardy" and "resilient" to high levels of stress. Professor Salvatore Maddi's initiative to provide "hardiness training" in order to produce resilient executives is a prime example (see American Psychological Association 2003 for a summary of Salvatore et al.'s Chicago longitudinal study of hardiness training for resilient outcomes).

Human resilience often eludes external onlookers whose mindsets are bound by academic theory and discipline-specific dogma. This state of affairs can problematize and turn a partially understood concept into types of research exercises that lead to different understandings. Some have generated more heat and smoke than light on their futile attempts to denigrate the concept that strikes them as neo-liberal (like "social capital" before it). Other researchers choose to first create resilience in their own image and then find it wanting. It is like making a pot called resilience and then smashing it to pieces because it did not deliver as a pot. Retrofitting the concept to "data-driven" standardized models has been tried, but data-driven is not the same as evidence-based. Data gathering, especially in laboratory settings, may be driven by purely theoretical assumptions that seem to home in on the word resilience as a disembodied construct where resilience is mis/ 
construed again as a neo-liberal portmanteau, far removed from the lives lived. It is no wonder that some confusion persists, and some researchers find it difficult to see the wood for the trees. Nevertheless, the phenomenon of human resilience pervades human lives and livelihoods in situations of extreme adversity across the planet. Harsh environments that challenge our species' survival and interconnected social-ecological, socio-cultural and geophysical sustainability challenges will continue to draw our attention to human resilience in all its dimensions.

\section{BACKGROUND}

The idea for this Special Feature originated from a roundtable discussion session that was organized and chaired by Lund University's Centre for Sustainability Studies (LUCSUS) and the division of Social Medicine \& Global Health (A. Almedom and P.-O. Östergren, unpublished manuscript) for the Eighth European Congress of Tropical Medicine and International Health convened in Copenhagen in 2013. Our session abstracts were subsequently published in a Special Issue of the journal Tropical Medicine and International Health (Invited Speakers 2013:31-33). The discussion was then opened up to facilitate a wider participation of interested authors with different perspectives and experiences of human resilience research and praxis in the context of interconnected health and social systems in different countries. In the process, it became apparent that wisdom prevailed over knowledge production and use. It transpired that wisdom played a pivotal role in imparting understanding of human resilience in the generation of knowledge in its multilayered dimensions. The dynamics of human resilience reflected complex adaptive systems in which actions influenced the systems and subsystems in which they were embedded. However, no single actor could control the outcome of her/his actions. At both the individual and collective levels, the sustainability of effective health and social systems and subsystems that are interconnected at micro, meso, and macro levels, as well as cross-scale depended on interactions between informed or knowledgeable actors that applied their wisdom and understandings of complexity effectively.

Human resilience studies continue to embrace multiple dimensions of complex system dynamics that are evident in human health and social well-being. Contributions to this Special Feature have tackled explicitly and implicitly three major themes that emerge from ongoing scientific and policy debates around the concept of human resilience.

First, the context in which human resilience is articulated in first person narratives, observed by onlookers, and discussed in research reports determines particular understandings of what it means to be or to become resilient. This naturally generates epistemological pluralism. Discipline-oriented methods of investigation and analysis can enrich or curtail the depths of understanding what is being narrated first hand, observed from a distance, and/or communicated by experts. Bergström and Dekker's article (2014) invites complex systems' thinkers and others from different disciplinary backgrounds to inform one another and cross-inspire themselves by applying the Joint Cognitive Systems Paradigm Theory, for example. Influenced by the late Paul Cilliers' seminal work on complex systems thinking theory as it applies to human cognition and behavior, they promote an ecological model of human cognition that is informed by the analytical powers of the mind as much as it is by the perceived or observed realities of the external world - the context. Human cognition emerges and is distributed through interactions and relationships between local actors.

Almedom et al.'s (2015) synthesis resonates with Bergström and Dekker's insight in that it elaborates on the need to acknowledge and employ epistemological pluralism on the grounds that knowledge of human resilience belongs to those whose lives depict it in complex and dynamic ways. Localized cognition and action at micro and meso levels can reverberate cross scale to either respond to or catalyze macro level perceptions and actions.

Second, and this is directly related to the theme of contextually constructed epistemological pluralism, human resilience is about localized complex adaptive system dynamics that are evident in human interactions at all levels: micro, meso, macro, and crossscale. It seems necessary to emphasize the human in human resilience because there is a tendency to "dehumanize" resilience when the term is used universally.

Third, narratives of human resilience fuel the sustainability of interconnected health and social systems across cultures. Douglas Glandon's (2015) contribution to this volume recounts some examples. The case of the Tofinu tribe of Benin is particularly poignant. Faced with the real threat of enslavement by the dominant Fon tribe of the Dahomey Kingdom in the 17th century, they took the most drastic action. They abandoned their land and began to rebuild their homes on stilts erected in Lake Nakoué. It was the only place for them to live free because of a Fon belief system that prevented aggression on communities whose dwellings are surrounded by water. The photo on the banner of this Special Feature shows a modern-day market day in Tofinu "island." It is a picture of resilience, a deep-rooted cultural heritage of survival and sustainability, more about community resilience than vulnerability to rising sea levels. What can island communities and those whose land is progressively going under water learn from the Tofinu's four-century-old technology of rebuilding villages on stilts? What are the implications for the current investment strategies of philanthropic, governmental, and nongovernmental organizations? This special feature aims to generate discussion and possible answers to such questions.

Matin and Taylor's (2015) findings from the flood-prone Sundrabands of western Bangladesh provides an example of studies of human resilience to disasters that combine a generalized understanding of ecosystem and economic resilience with human psychosocial resilience. In the aftermath of cyclone Aila of 2009, the coastal communities were hard hit. Although bamboo platforms were in use, they were inadequate to protect lives and livelihoods. Multiple methods were used, including individual life histories, assessments of "mastery" and "self-efficacy," and the multidimensional "sense of coherence (SOC)" scale, short form. In the authors' eagerness to review the source materials, they decided to retranslate item 10 of the scale, opting for the idea of "losing the battle of life" (closer to Antonovsky's notion of "sad sacks (losers)" applied to a New York setting). It is interesting to note that they still found hope and/or optimism emerge as a more relevant component of human resilience. Because they did not look at the subscales of the SOC-13 in their analysis, it is not possible to compare the findings with those of other studies that employed the SOC-13 and further developed it to the SSOC (sense 
and sensibilities of coherence). The study contributes to our understanding of human resilience by drawing on both trauma studies that assume that human resilience is the successful management or even absence of trauma in the face of extreme adversity, and qualitative descriptions of individual life histories. Social scientists of various disciplinary backgrounds would be expected to engage with this contribution as we look forward to continued discussions of human resilience in the context of interconnected health and social systems.

"Resilience in the individual is dependent on multiple layers of society" (Sippell et al. 2015). This is a an important observation stated by medical practitioners in neurobiology and psychiatry who find that social support plays a key role in promoting and enhancing human resilience. They examined studies of severely traumatized individuals including, but not only American military combat veterans. They found common threads of human resilience stemming from an integrated view of the social, biological, and physiological systems' integrity. Individuals nested in romantic, familial, community, and professional relationships that are governed by functional social support turned out to be more helpful to those more effectively supported than those in only structural networks. The authors provide a unique analysis of the interconnected, individual-level genetic, neurological, physiological, and behavioral components of social interactions that result in positive or negative aftermath of traumatic experiences. It is particularly poignant to learn from this contribution that human resilience largely depends on the quality and quantity of social capital invested in peer groups and communities of solidarity and emotional safety. Their persuasive arguments resonate with previous findings in anthropology and the behavioral sciences that social support (like social capital) can be good and bad depending on the type, timing, and levels of intervention. Implicit in this discussion is the role of agency. Human resilience, whether at individual, family, or community level cannot be engineered by external actors, however wellmeaning. It is important to start from the realities of those experiencing extreme adversity and to engage them in the questions pertaining to their mental and emotional health.

This point is emphasized by Almedom et al. (2015) in the context of the need to reconcile epistemological plurality and knowledge generation with clear motives that enhance rather than undermine human resilience at any level. Because, as Bergström and Dekker 2015 also discussed, human resilience presents itself as fractal, the principles that apply to micro, meso, and macro level analysis are intrinsically the same.
Responses to this article can be read online at: http://www.ecologyandsociety.org/issues/responses. php/8195

\section{Acknowledgments:}

The Rockefeller Foundation (New York) provided research funds that supported this work at Lund University's Centre for Sustainability Studies in Sweden. Stephen Flynn (Northeastern University's Center for Resilience Studies) and Johan Bergström (Lund University's Centre for Societal Resilience) stepped in at different times to provide administrative editorial support during the preparation of this Special Feature. Several anonymous peer reviewers engaged with us generously and diligently. I thank them all.

\section{LITERATURE CITED}

Almedom, A. M., D. O’Byrne, and A. Jerneck. 2015. Principles of epistemological accountability with methodological implications for measuring, assessing, and profiling human resilience. Ecology and Society 20(3):9. http://dx.doi.org/10.5751/ ES-07313-200309

American Psychological Association. 2003. Turning lemons into lemonade: hardiness helps people turn stressful circumstances into opportunities. American Psychological Association, Washington, D.C., USA. [online] URL: http://www.apa.org/research/action/ lemon.aspx

Bergström, J., and S. W. A. Dekker. 2014. Bridging the macro and the micro by considering the meso: reflections on the fractal nature of resilience. Ecology and Society 19(4):22. http://dx.doi. org/10.5751/ES-06956-190422

Glandon, D. M. 2015. Measuring resilience is not enough; we must apply the research. Researchers and practitioners need a common language to make this happen. Ecology and Society 20 (2):27. http://dx.doi.org/10.5751/ES-07576-200227

Invited Speakers. 2013. Invited Speakers' abstracts. Tropical Medicine and International Health 18(S1):7-51. [online] URL: http://onlinelibrary.wiley.com/doi/10.1111/tmi.12161/abstract

Matin, N., and R. Taylor. 2015. Emergence of human resilience in coastal ecosystems under environmental change. Ecology and Society 20(2):43. http://dx.doi.org/10.5751/ES-07321-200243

Sippel, L. M., R. H. Pietrzak, D. S. Charney, L. C. Mayes, and S. M. Southwick. 2015. How does social support enhance resilience in the trauma-exposed individual? Ecology and Society 20(4):10. http://dx.doi.org/10.5751/ES-07832-200410 